\title{
Pharmacologic and Clinical Considerations of Nalmefene, a Long Duration Opioid Antagonist, in Opioid Overdose
}

\author{
Amber N. Edinoff ${ }^{1, *}$, Catherine A. Nix ${ }^{1}$, Tanner D. Reed ${ }^{2}$, Elizabeth M. Bozner ${ }^{2}$, Mark R. Alvarez ${ }^{3}$, \\ Mitchell C. Fuller ${ }^{4}$, Fatimah Anwar ${ }^{5}$, Elyse M. Cornett ${ }^{6}$, Adam M. Kaye ${ }^{7}$ (D) and Alan D. Kaye ${ }^{6}$ (D) \\ 1 Department of Psychiatry and Behavioral Medicine, Louisiana State University Health Shreveport, \\ Shreveport, LA 71103, USA; catherine.nix@lsuhs.edu \\ 2 School of Medicine, Louisiana State University Health New Orleans, New Orleans, LA 70112, USA; \\ treed8@lsuhsc.edu (T.D.R.); ebozne@lsuhsc.edu (E.M.B.) \\ 3 School of Medicine, Louisiana State University Health Shreveport, Shreveport, LA 71106, USA; \\ mra001@lsuhs.edu \\ 4 School of Medicine, Medical College of Wisconsin, Milwaukee, WI 53226, USA; mfullermcw@gmail.com \\ 5 Department of Psychology, University of New Haven, West Haven, CT 06516, USA; fanwar0261@gmail.com \\ 6 Department of Anesthesiology, Louisiana State University Shreveport, Shreveport, LA 71103, USA; \\ elyse.bradley@lsuhs.edu (E.M.C.); alan.kaye@lsuhs.edu (A.D.K.) \\ 7 Department of Pharmacy Practice, Thomas J. Long School of Pharmacy and Health Sciences, \\ University of the Pacific, Stockton, CA 95211, USA; akaye@pacific.edu \\ * Correspondence: amber.edinoff@lsuhs.edu; Tel.: +1-318-675-8969
}

Citation: Edinoff, A.N.; Nix, C.A.; Reed, T.D.; Bozner, E.M.; Alvarez, M.R.; Fuller, M.C.; Anwar, F.; Cornett, E.M.; Kaye, A.M.; Kaye, A.D. Pharmacologic and Clinical Considerations of Nalmefene, a Long Duration Opioid Antagonist, in Opioid Overdose. Psychiatry Int. 2021 2,365-378. https://doi.org/10.3390/ psychiatryint 2040028

Academic Editor: Domenico De Berardis

Received: 23 August 2021

Accepted: 8 October 2021

Published: 14 October 2021

Publisher's Note: MDPI stays neutral with regard to jurisdictional claims in published maps and institutional affiliations.

Copyright: (c) 2021 by the authors. Licensee MDPI, Basel, Switzerland. This article is an open access article distributed under the terms and conditions of the Creative Commons Attribution (CC BY) license (https:// creativecommons.org/licenses/by/ $4.0 /)$.
Abstract: Opioid use disorder is a well-established and growing problem in the United States. It is responsible for both psychosocial and physical damage to the affected individuals with a significant mortality rate. Given both the medical and non-medical consequences of this epidemic, it is important to understand the current treatments and approaches to opioid use disorder and acute opioid overdose. Naloxone is a competitive mu-opioid receptor antagonist that is used for the reversal of opioid intoxication. When given intravenously, naloxone has an onset of action of approximately $2 \mathrm{~min}$ with a duration of action of 60-90 min. Related to its empirical dosing and short duration of action, frequent monitoring of the patient is required so that the effects of opioid toxicity, namely respiratory depression, do not return to wreak havoc. Nalmefene is a pure opioid antagonist structurally similar to naltrexone that can serve as an alternative antidote for reversing respiratory depression associated with acute opioid overdose. Nalmefene is also known as 6-methylene naltrexone. Its main features of interest are its prolonged duration of action that surpasses most opioids and its ability to serve as an antidote for acute opioid overdose. This can be pivotal in reducing healthcare costs, increasing patient satisfaction, and redistributing the time that healthcare staff spend monitoring opioid overdose patients given naloxone.

Keywords: nalmefene; opioid overdose; naloxone; harm reduction; antidote

\section{Introduction}

Reaching an equilibrium between the use of opioids for chronic pain, while balancing abuse and overdose risk has been a pertinent, costly challenge in medicine for decades [1]. Before 1990, physicians were reprimanded for the meager treatment of pain, followed by a shift toward aggressive opioid pain treatment in the late 1990s [2]. From 2011 to 2020, prescriptions for opioids decreased by more than $60 \%$; however, overdose deaths increased by approximately two times during the same time frame $[3,4]$. Now, we are fighting a recent rise in preventable overdose deaths that sparked in 2019 with the more frequent use of fentanyl, which can be more potent, long-lasting, and cheaper than heroin [5,6]. Fentanyl is easier to synthesize and is more potent than heroin, becoming a more commonly abused drug in the U.S. [7]. 
The CDC reported in July 2021 that overdose deaths in 2020 displayed the largest increase in nearly 50 years, from 70,980 deaths in 2019 to 93,331 deaths in 2020 [8]. Additionally, deaths caused by opioid-derived substances rose from nearly $70 \%$ in 2019 to approximately $75 \%$ in 2020 [8]. The COVID-19 pandemic and its consequences are suspected of having played a significant role in the rise.

The primary drug for combatting acute opioid overdose has been naloxone. In overdose situations and for clinical uses, the respiratory depression and sedative effects of opioids can occur for several hours after administration $[9,10]$. This requires more hours of patient monitoring for signs of respiratory depression and potential repeated administration of naloxone, as the duration of action (DOA) of naloxone is generally $64 \mathrm{~min}$ [11]. This brings light to the pertinent issue associated with naloxone: its DOA is less than that of most frequently abused opioids $[12,13]$.

This central issue with naloxone has led much research toward an alternative opioid antagonist with a longer DOA. Nalmefene is a pure opioid antagonist structurally similar to naltrexone that can serve as an alternative antidote for reversing respiratory depression associated with acute opioid overdose. The key feature of nalmefene is its increased DOA being several hours longer than naloxone and its ability to serve as an antidote during acute opioid overdose, unlike naltrexone. This can help patients be discharged earlier and decrease nursing observation by $2-4 \mathrm{~h}[11,12]$. An alternative opioid overdose antidote on the market is further beneficial with the marked rise in opioid overdose deaths.

On 13 March 2019, the U.S. Food and Drug Administration (FDA) granted Fast Track designation for Purdue Pharma L.P.'s Nalmefene $\mathrm{HCl}$ injections to treat known or suspected opioid overdose [14]. Reasons for Fast Track designation include the marked rise in opioid overdoses in the U.S. and the subsequent need for more reversal agents of similar or better efficacy than naloxone.

Though nalmefene has displayed efficacy in treating alcohol dependence in humans [15], this review will focus on nalmefene's implications with opioid use disorder (OUD) and opioid overdose. This study was designed to analyze the efficacy and practicality of nalmefene treatment in OUD and suspected opioid overdose cases by reviewing the history of nalmefene research in human subjects.

\section{Opioid Use Disorder/Overdose}

Opioid analgesics are widely regarded as a necessary and legitimate medical therapy for people suffering from severe acute pain and chronic pain that is unresponsive to other therapies. Therapeutic success is dependent on proper patient selection, administration, and close monitoring throughout treatment [16]. However, opioid misuse and substance use disorders have imposed a major health epidemic on the United States population. From 1999 to 2017, more than 700,000 U.S. residents died from a drug overdose, and over two-thirds were attributable to opioids [17]. In U.S. adults aged 24 to $35,20 \%$ of all deaths are attributable to opioids [18]. Given the burden of the opioid epidemic on our society, an understanding of the problem we face may equip medical personnel with the knowledge to cultivate a safer therapeutic environment for the future.

Opiates such as morphine and heroin, naturally derived from the opium poppy, were first recognized in the 1800s and marketed to physicians and patients as a safe and effective way to alleviate suffering [19]. Opiates were employed freely to treat everyday conditions, including cough, diarrhea, mild pain, and anxiety. Increased use brought awareness to the disadvantages by way of the 1915 Harrison Anti-Narcotic Act [20]. These initiatives sought to decrease opiate consumption through regulation of opiate prescribing and dispensing practices. Attitudes towards opioid safety and prescribing practice changed in the 1980s; an editorial in Advances in Alcohol and Substance Abuse wrote that physicians markedly undertreat pain in addition to expressing concern for "opiophobia" as an undocumented and illegitimate fear that patients will become addicted to opioids when used appropriately [21]. Popular thought shifted during this time, favoring heavy analgesia coverage over the side effect profile of narcotics. In conjunction with unsubstantiated 
physician-targeted marketing schemes by pharmaceutical companies purporting superior safety profiles in extended-release oxycodone, subscribing rose steadily until a peak in 2010 at 225 million prescriptions [22]. That was equal to over 81 prescriptions per 100 persons in the U.S. Additionally, there was a rise in non-medical use or diversion in the U.S., wherein between 1999 and 2009, death rates involving prescription opioids increased four-fold [23].

\section{Current Treatment of Opioid Use Disorder/Overdose}

Opioid use disorder is a well-established and growing problem in the United States responsible for both psychosocial and physical damage to the affected individuals, in addition to a nearly 10-fold higher mortality rate relative to the general public [24]. Given both the medical and non-medical consequences of this epidemic, it is important to understand the current treatments and approaches to acute opioid overdose.

Naloxone is a competitive mu-opioid receptor antagonist used to reverse opioid intoxication [25]. When given intravenously, naloxone has an onset of action of approximately 2 min with a duration of action of 60-90 min [25]. Related to its empirical dosing and short duration of action, frequent monitoring of the patient is required so that the effects of opioid toxicity, namely respiratory depression, do not return to wreak havoc [25]. Naloxone has few adverse effects which are commonly linked to withdrawal from opioids, such as anxiety, aggression, nausea, vomiting, diarrhea, abdominal pain, and rhinorrhea [26].

Despite the advantages of naloxone in treating acute opioid overdose, emergency departments prescribe and dispense naloxone relatively infrequently [27]. A group of surveyed emergency departments in New England demonstrated that only 12\% would prescribe naloxone at discharge for patients at high risk of overdose. A similar survey of 200 emergency department physicians demonstrated a broad acceptance and willingness to improve opioid harm-reduction strategies. Still, it also revealed that of the surveyed physicians, only $1.7 \%$ had personally prescribed naloxone, and only $10.3 \%$ had referred at-risk patients to naloxone distribution programs [27].

Another basic pillar in addressing the risks of opioid overdose and fatality is public access to naloxone and overdose education programs (OEPs). Reviews conducted by both the World Health Organization and the Canadian Agency for Drugs and Technologies in Health established that OEPs have demonstrated success in reducing fatality from overdose [28,29]. Mitchell et al. describe the success public policy has had as well, citing the successes of government-funded naloxone distribution programs in Scotland, England, and Canada, and in California, Massachusetts, New York, Rhode Island, and North Carolina in the United States [28]. One program based in San Francisco found that approximately 21\% of program participants had used naloxone to reverse an opioid overdose, with a documented $89 \%$ success rate [28]. These educational programs should be directed at healthcare providers, as well. Through an educational program run by the United States Veterans Health Administration, naloxone prescription rates tripled in 12 months and septupled by 24 months [27]. Policies aimed at reducing liability for naloxone prescriptions, increasing public access to and education of naloxone use, and encouraging/mandating co-prescribing of naloxone with opioids have all been shown to reduce overdose fatalities [25,27-29].

A discussion of OUD treatment would be remiss if it did not include a discussion of naltrexone. Naltrexone is a $\mu$-opioid receptor (MOR) and is used for both the treatment of alcohol use disorder and OUD. It also blocks delta and kappa receptors, as well. Naltrexone blocks the euphoric effects of opioids and is used to reduce and suppress cravings [30]. Naltrexone cannot, however, reverse an overdose or treat opioid withdrawal. It is used alone or can be combined in a formulation with buprenorphine to reduce the potential for abuse. Nalmefene is structurally similar to naltrexone, but it has a longer half-life and better bioavailability.

\section{Nalmefene}

Nalmefene $\mathrm{HCl}$ is a pure opioid receptor antagonist and is considered the longestacting parenteral opioid antagonist commercially available for OUD and opioid overdose. 
It is a white crystalline substance, and its chemical name is 17 -(cyclopropylmethyl)-4,5epoxy-6-methylenemorphinan-3,14-diol, hydrochloride salt. It can be used to prevent or counter the various consequences of opioid overdose or post-surgery opioid effects, such as respiratory depression and sedation. Desirable outcomes of nalmefene administration include alleviation of respiratory depression, nerve center depression, and hypotension associated with prolonged opioid receptor activation [31]. A pill form of nalmefene is manufactured in Japan, England, and other European countries under the brand name of Selincro ${ }^{\circledR}$ for the treatment of alcohol dependence in decreasing alcohol intake [32].

In 1995, nalmefene $\mathrm{HCl}$ was granted approval by the U.S. FDA to treat known or suspected opioid overdose and was sold under the brand name Revex ${ }^{\circledR}$. Nalmefene can be administered intravenously (IV), intramuscularly (IM), or subcutaneously (SC). Nalmefene is currently sold in two doses, with the concentration being dependent on postoperative or overdose use. Nalmefene is available in a blue-labeled ampul containing $1 \mathrm{~mL}$ at a concentration of $100 \mu \mathrm{g} / \mathrm{mL}$ for postoperative use. For opioid overdose reversal, nalmefene is available in a green-labeled ampul containing $2 \mathrm{~mL}$ at a $1 \mathrm{mg} / \mathrm{mL}$ concentration, being ten times more concentrated than the postoperative formulation [33]. An initial dose of $0.5 \mathrm{mg} / 70 \mathrm{~kg}$ for opioid overdose reversal is recommended and can be followed up 2-5 min with a $1.0 \mathrm{mg} / 70 \mathrm{~kg}$ dose [33]. Intravenously administration of nalmefene generally takes $2 \mathrm{~min}$ for initiation of opioid reversal [33]. If nalmefene is administered via intramuscular (IM) or subcutaneous (SC) routes, it may take 5-15 $\mathrm{min}$ for a $1 \mathrm{mg}$ dose to be effective [31].

Nalmefene is well tolerated in human subjects for up to $24 \mathrm{mg}$ of IV doses [34]. In most studies, its side effects were transient, relatively mild, and similar to naloxone's side effects. The main side effects for both are nausea, vomiting, tachycardia, hypertension, pain, fever, and dizziness [31]. However, it can produce acute withdrawal symptoms in those physically dependent on opioids [31]. Furthermore, nalmefene is only known to have net antagonistic effects on opioid receptors and is not considered abuse potential nor cause physical dependence [29].

Special caution should be considered with administering nalmefene to pregnant or nursing mothers, neonates, pediatric patients, and patients over 65 years of age. There has not been sufficient research in these populations to deem it safe for use. Regarding reproduction, it is worthy to note that nalmefene did not affect fertility in rats, and its partial kappa-opioid receptor activity was found to increase serum prolactin levels and luteinizing hormone pulsatility in humans $[35,36]$.

\subsection{Mechanism of Action}

Nalmefene is structurally similar to naltrexone and also known as 6-methylene naltrexone [37]. The 6-methylene group in nalmefene replaces the 6-ketone group of naltrexone. Its methylene group is suspected to result in increased DOA, higher affinity at MOR, a G-protein coupled receptor [38]. It has a greater oral bioavailability relative to naloxone [39-42]. It acts as an opioid receptor modulator on $\mu-, \mathrm{K}-$, and $\delta$-opioid receptors.

$\mathrm{K}$-opioid receptors (KORs) aid in mediating sedation and partially respiratory depression [9]. MORs play an important role in euphoria, physical dependence, and the respiratory depression associated with opioid overdose [9,43]. 8 -opioid receptors (DORs) are implicated with positive affect and decreased anxiety [43].

Nalmefene is known to be a competitive antagonist at the $\mu$ - and $\delta$-opioid receptors [44]. It has the strongest affinity and antagonistic effects at MOR, responsible for the decreased response to $\mathrm{CO}_{2}$ and subsequent respiratory depression associated with opioid overdose [45]. These antagonistic effects are critical for its use as a reversal agent upon injection to halt the potentially fatal effects of respiratory depression and sedation caused by acute opioid overdose.

Nalmefene possesses partial agonistic affinity at k-opioid receptors (KOR), and partial agonism of KOR leads to a net antagonistic effect. Studies suggest that its action at KOR decreases dopamine in the nucleus accumbens and subsequent inhibition of the positive reinforcement associated with the mesolimbic reward pathway [37]. Because ethanol leads 
to a rise in endogenous opioids such as $\beta$-endorphin, a MOR agonist, and dynorphin, a KOR agonist, orally administered nalmefene effectively combats their effects and decreases alcohol consumption in combination with psychosocial support [31].

Nalmefene possesses MOR and KOR binding affinities comparable to naloxone [36]. Nalmefene has the greatest affinity for KOR, followed closely by MOR, and significantly less affinity for DOR [36]. Its affinity for DORs is 200-fold less than its affinity for KOR and can be considered to play a smaller role in its physiological effects [36].

Nalmefene also has a higher potency for opioid receptors than naloxone. Its potency is 4 times higher than naloxone at MOR and slightly more potent at KOR [46]. Nalmefene also has a longer elimination half-life, ranging from 8 to $11 \mathrm{~h}$, and a longer duration of action of 1-4 $\mathrm{h}$ [46]. The longer duration of action is also associated with the medication's slow dissociation from the opioid receptor [46].

\subsection{Pharmacokinetics/Pharmacodynamics}

Pharmacodynamic studies have found a clinically competent reversal of opioid effects, including respiratory depression, sedation, and hypotension. Nalmefene has a longer DOA than naloxone at fully reversing doses with zero agonist activity [31]. The same studies have not reproduced any respiratory depression, sedation, hypotension, psychotomimetic effects, or pupillary constriction. There was no pharmacological activity observed when nalmefene was administered in the absence of opioid agonists. Nalmefene has not been shown to produce physical dependence, tolerance, or abuse potential, although it can produce acute withdrawal symptoms in opioid-dependent individuals.

The pharmacokinetic profile of nalmefene is complex and has been intensely studied. It is absorbed with complete bioavailability following IM and subcutaneous administration relative to IV in 12 subjects [31]. As a result, nalmefene will routinely be given as an IV bolus, but in failed venous access, it can also be given SC or IM with superior efficacy. Time to maximum plasma concentration is $2.3 \mathrm{~h} \pm 1.1 \mathrm{~h}$ following IM administration compared to $1.5 \mathrm{~h} \pm 1.2 \mathrm{~h}$ following SC administration and 5-15 min after $1 \mathrm{mg}$ IV bolus in emergencies. Nalmefene is distributed rapidly following a $1 \mathrm{mg}$ parenteral dose, blocking over $80 \%$ of brain opioid receptors within $5 \mathrm{~min}$. The steady-state concentration is reached at $8.6 \pm 1.7 \mathrm{~L} / \mathrm{kg}$. Ultrafiltration studies demonstrated that $45 \%$ of nalmefene is bound to plasma proteins and distributed in a 2:1 ratio of RBC:plasma [31]. Population kinetic models have shown that nalmefene distribution is age-dependent, with elderly populations having a faster distribution half-life, a smaller volume of distributions $\left(\mathrm{V}_{\mathrm{d}}\right)$, and higher initial concentrations than younger populations [47]. The liver primarily metabolizes nalmefene in a glucuronide conjugation reaction with subsequent excretion in urine [48]. The N-dealkylated metabolite has minimal pharmacologic activity. Nalmefene is eliminated biexponentially with a systematic clearance of $0.8 \pm 0.2$ liters/hour/kilogram and renal clearance of $0.08 \pm$ liters/hour/kilogram [48]. In summary, a robust population PK model found that a single 20 milligram dose of nalmefene produced a $24 \mathrm{~h}$ therapeutic effect in $95 \%$ of the population [49].

\section{Nalmefene vs. Naloxone}

Nalmefene and naltrexone are pure opioid antagonists that block receptor activity of the mu, kappa, and delta sub receptors in the CNS [50]. Nalmefene is a methylene analog of naltrexone that was originally approved in 1995 as a more potent analog. Nalmefene is has a slightly slower onset of action when given IV (5-15 min compared to 1-2 min with naloxone), equipotent binding power compared to naloxone, a longer DOA, and a much longer plasma half-life (8-11 h compared to $80 \mathrm{~min}$ with naloxone) [51]. Both naloxone and nalmefene are indicated in acute opioid intoxication characterized by respiratory depression, coma, or hypotension. Off-label uses for both agents include clonidine, benzodiazepine, ethanol, or valproic acid overdoses [52]. Overall, both agents are useful for acute opioid withdrawal despite a longer DOA, similar potency, and a longer onset of action is seen in nalmefene compared to naloxone. 


\section{Naltrexone}

Naltrexone is a pure opioid antagonist and is used for the reduction of cravings and consumption of both opioids and alcohol. Of note, naltrexone is not indicated for acute opioid intoxication. In fact, naltrexone has been implicated in acute opioid overdose deaths as it can lower the patient's tolerance to opioids. These overdoses happen after a period of abstinence and discontinuation of naltrexone [30]. This makes them more susceptible to overdose with a smaller amount of opioids used than in the past.

Naltrexone comes in an oral or a long-acting injectable form, called vivitrol. Historically, patients would have to show that oral naltrexone was tolerable without an increase in liver function enzymes prior to starting the injectable form. It is because of this that naltrexone has not been useful in an acute overdose situations since oral medicine cannot be given to someone who is unconscious. The injectable form comes with another set of barriers. Each injection is costly, at around USD 1400 a shot. It is because of this that not all pharmacies can afford to carry it, let alone have it accessible for emergency medical services. Table 1 shows a comparison of naloxone, nalmefene, and naltrexone.

Table 1. The comparison of naloxone, nalmefene, and naltrexone.

\begin{tabular}{|c|c|c|c|c|}
\hline Medication & $\begin{array}{l}\text { Mechanism } \\
\text { of Action }\end{array}$ & Pharmacokinetics/Dynamics & Uses & $\begin{array}{c}\text { Routes of } \\
\text { Administration }\end{array}$ \\
\hline Naloxone & $\begin{array}{l}\text { Antagonist } \\
\text { of MOR }\end{array}$ & $\begin{array}{l}\text { Half-life: } 30-120 \mathrm{~min} \\
\text { Duration of Action: } 1-4 \mathrm{~h} \\
\text { Metabolized by: Liver }\end{array}$ & $\begin{array}{l}\text { Reversal of } \\
\text { Opioid Overdose }\end{array}$ & $\begin{array}{l}\text { Intranasal } \\
\text { Subcutaneous } \\
\text { Endotracheal } \\
\text { Sublingual } \\
\text { Intralungual } \\
\text { Submental } \\
\text { Intravenous } \\
\text { Intramuscular }\end{array}$ \\
\hline Nalmefene & $\begin{array}{l}\text { Antagonists at } \\
\text { MOR and } \\
\text { DOR } \\
\text { Partial agoist } \\
\text { at KOR }\end{array}$ & $\begin{array}{l}\text { Half-life: } 8-11 \mathrm{~h} \\
\text { Duration of action: } 1-4 \mathrm{~h} \\
\text { Metabolized by: Liver }\end{array}$ & $\begin{array}{l}\text { Reversal of } \\
\text { Opioid Overdose }\end{array}$ & $\begin{array}{l}\text { Intravenous } \\
\text { Intramuscular } \\
\text { Subcutaneously }\end{array}$ \\
\hline Naltrexone & $\begin{array}{l}\text { Pure } \\
\text { antagonist at } \\
\text { the MOR, } \\
\text { DOR, } \\
\text { and KOR }\end{array}$ & $\begin{array}{l}\text { Half life: } 4 \mathrm{~h} \text { for naltrexone } \\
\text { and } 13 \mathrm{~h} \text { for active metabolite } \\
\text { of } 6 \text { beta-naltrexol } \\
\text { Duration of action: } \\
\text { Metabolized by: Liver }\end{array}$ & $\begin{array}{l}\text { Can reduce and } \\
\text { suppress opioid } \\
\text { and alcohol } \\
\text { cravings } \\
\text { Not used in } \\
\text { opioid overdose }\end{array}$ & $\begin{array}{l}\text { Oral } \\
\text { Intramuscular }\end{array}$ \\
\hline
\end{tabular}

\section{Clinical Studies: Safety and Efficacy}

A broad array of studies has investigated both the clinical efficacy and safety of nalmefene, especially as an acute treatment for opioid toxicity. In a review of the literature, the following articles were chosen to best summarize and relay the relevant findings.

\subsection{Kaplan Study}

Kaplan et al. analyzed the differences between nalmefene and naloxone pharmacotherapy to treat suspected narcotic overdose in emergency department settings, specifically evaluating differences in efficacy, safety, and symptoms of opioid withdrawal [11]. This study compiled data from adult patient populations ( $\geq 18$ years old) across nine primarily urban teaching hospitals in the United States, randomizing those patients selected into one of three treatment arms: up to four doses of either 1 milligram nalmefene, 2 milligram nalmefene, or 2 milligram naloxone over the four-hour-long study [11]. All of this was conducted double-blindly, with the treatment arms randomized and the study drugs prepared by and labeled indistinguishably by an outside facility [11]. Endpoints were measured using respiratory rate, Neurobehavioral Assessment Scale (NAS) scores, Opioid Withdrawal Scale (OWS) scores, and the recorded incidents of adverse events following treatment [11]. A respiratory rate of 4 breaths/minute was assumed [11]. In addition to evaluating the 
drug's effects on the patients, corresponding labs were drawn to quantify the concentration of nalmefene in the patients' plasma, with samples being drawn at 2- and 4-h intervals [11].

A total of 171 unique patients were evaluated on 176 emergency department (ED) visits. Approximately half of the patients in each of the three treatment arms tested positive for opioids during their visits [11]. Posing a complication to this study's evaluation was that $>90 \%$ of the opioid-positive patients included also tested for additional illicit substances [11]. In each of the three treatment arms, changes to respiratory rates and the NAS scores were similar, with both improving over time with the assigned treatments [11]. However, when the data were stratified based on the patients' screening positive for opioid toxicity during their ED visit, more dramatic improvements to those measures were noted [11]. In looking at the nalmefene groups, an improvement in the NAS scores was noted over the trended interval from $20 \mathrm{~min}$ post-administration to $240 \mathrm{~min}$, whereas those of the naloxone groups demonstrated a decrease, and these differences were not statistically significant [11].

In evaluating the safety of the varying treatment arms, Kaplan et al. analyzed the 1 milligram nalmefene group against the naloxone group, chosen since naloxone is the current standard of care for these patient visits [11]. Of those reporting adverse events rated from mild to severe, over $30 \%$ of patients in the 2 milligram nalmefene treatment arm experienced negative side effects, the most common of which were vomiting, nausea, and tachycardia [11]. However, there were no clinically or statistically significant differences between the 1 milligram nalmefene and the naloxone groups as evaluated by the efficacy measures described in detail above, nor were there any significant differences between the opioid-positive and negative groups [11]. Additionally, recorded vitals from both opioid-positive and opioid-negative patient groups did not differ significantly from one another, and all of the reported negative outcomes and side effects were determined by the researchers not to have been related to either of the doses of nalmefene [11].

While there was no statistical or clinical difference noted among the three treatment arms, Kaplan et al. acknowledge several limitations in their analysis. Related to the high rate of multiple substances intoxicating, especially the opioid-positive patients, the researchers note that a lack of recorded response to the study drugs does not preclude opioid receptor antagonism, as the observed clinical signs attributed to opioid intoxication could very well be related to other non-opioid substances [11]. Additionally, multiple patients recorded as having responded to the study drugs were not confirmed to be opioidpositive by lab analysis, thus allowing for real potential differences in treatment arms that were not detected by the study [11]. Conversely, suppose those who were falsely stratified as opioid-negative were not equally distributed. In that case, bias could be introduced into the results with the potential to mask a true difference among the treatment arms [11]. The authors also raised questions regarding their study's external validity, as all participants in this study were treated in strictly urban teaching hospitals [11].

\subsection{NIH Study}

A different study conducted by Krieter et al. at the National Institute of Health (NIH) sought to compare intranasal and intramuscular nalmefene as the acute treatment for opioid overdose [53]. Data were collected from male and female inpatient participants aged 18 to 55 years old, with groups randomly assigned to one of six four-series treatment sequences in a double-blind manner [53]. Each of the treatment doses were as follows: 3 milligram intranasal nalmefene; 3 milligram $0.25 \%$ intranasal nalmefene-dodecyl maltoside (DDM); 1.5 milligram intranasal nalmefene; and 1.5 milligram intramuscular nalmefene. To form the six different treatment sequences, each participant was randomized to one of the intranasal nalmefene groups while each subject received the intramuscular nalmefene as their final study dosage [53]. These intranasal nalmefene dosages were selected due to the documented bioavailability of intranasal naloxone, a drug bearing significant structural similarity to nalmefene [53]. Data were collected on subjects via ECG and venous blood samples for plasma drug concentration, each collected at varying intervals from baseline to $72 \mathrm{~h}$ post-administration of their treatment drug [53]. Additionally, researchers monitored 
for adverse events by grading subjects' experienced intranasal irritation and repeated testing for the subjects' retained sense of smell following the repeated administration of intranasal medications [53].

Ten subjects fully completed the study requirements, including all the follow-up parameters [53]. In the 3 milligram nalmefene group, labs could detect plasma drug concentrations by the sample collected at $15 \mathrm{~min}$ post-administration [53]. However, in analyzing plasma drug concentrations of patients treated with the adjuvant of $0.25 \%$ DDM, the nalmefene levels were quantifiable by as little as $5 \mathrm{~min}$ [53]. In further analyzing the drug concentrations trended out over $72 \mathrm{~h}$, the addition of DDM to nalmefene reduced the estimated time to maximum blood concentration from approximately $2 \mathrm{~h}$ to $15 \mathrm{~min}$, while also increasing the maximum plasma concentration by nearly double that of nalmefene alone [53]. The addition of DDM to the intranasal nalmefene solution did not, however, appear to alter the drug's rate of elimination relative to nalmefene alone [53]. Ten of the fourteen original study subjects experienced some degree of adverse effects of the study drugs, most of which were vomiting, nausea, and dizziness [53]. All of these reported negative outcomes were mild in severity, and there was no loss or alteration to the sense of smell noted by any of the study subjects [53].

Despite the improvements noted in overall pharmacodynamics and following a review of relevant research, Krieter et al. do not suggest that these improvements, however nominally impressive, actually result in any changes in patient outcomes [53]. An obvious issue with this study includes limitations in overall generalizability due to the small sample size involved; as such, broad-reaching inferences and conclusions regarding the observed pharmacodynamics are highly limited [53].

\subsection{Tufts University Study}

A study conducted by Connelly et al. at the Tufts University School of Medicine attempted to evaluate nalmefene versus naloxone as prophylaxis against adverse effects of intrathecal opioids in the specific patient subset of those undergoing cesarean delivery [54]. The stated goal was to discover which treatment arms demonstrated the greatest reduction in opioid-induced side effects while not compromising the initial intrathecal anesthetic [54]. At the start of the study, 80 patients were randomly assigned in a double-blind manner to one of four treatment arms: saline, 0.25 microgram/kilogram intravenous nalmefene every $12 \mathrm{~h}$ for two doses, 0.50 microgram/kilogram intravenous nalmefene every $12 \mathrm{~h}$ for two doses, and a $48 \mathrm{mcg} / \mathrm{h}$ naloxone infusion [54]. The intrathecal agents administered to the subjects involved in the study were 50-70 milligrams of lidocaine with epinephrine (200 micrograms), 10 micrograms of fentanyl, and 0.2 milligrams of morphine [54]. Endpoints were evaluated via Visual Analog Scores (VAS) to collect data at varying intervals on the patients' pain, sedation, and overall satisfaction with their spinal block [54].

The investigators found no statistical or clinical differences among the treatment arms over the first day of observation, with no noted differences in recorded pain levels or patient satisfaction [54]. Additionally, no difference among the varying groups was noted about pruritis or nausea; however, a statistically significant increase in the rate of occurrence of instances of vomiting was higher in both of the nalmefene treatment arms than that of the control saline group [54].

Limitations to this study include the base assumption that the side effects being monitored (pruritis, nausea, and vomiting) were strictly related to the opioid receptor antagonism attained by the patients' spinal blocks, as they are far more likely to be multifactorial [54]. Anecdotal evidence from the authors' own clinical experience has shown that the adverse effects of opioid spinal blocks are largely unrelieved by a reduction in the intrathecal dosing of those opioid agents [54]. Additionally, looking at the other literature on the topic, multiple studies have demonstrated naloxone's inability to reduce the negative side effects of the spinal blocks without lowering the therapy's analgesic capabilities [54]. Overall, related to the lack of evidence that treating these adverse effects prophylactically makes any difference in patient outcomes, and due to the increased risks of vomiting in 
both of the nalmefene groups relative to the naloxone group, Connelly et al. recommend that physicians treat these side effects as they arise [54].

\subsection{Nalmefene: Treating Opioid-Induced Respiratory Depression}

Konieczko et al. conducted a study specifically to analyze nalmefene's ability to resolve respiratory depression induced by morphine, especially relative to that accomplished by the relatively short-lived naloxone with its half-life of 1-2.5 $\mathrm{h}$ [42]. The researchers used the values of end-tidal $\mathrm{PCO}_{2}$, rate of ventilation, and the subject's response to hypercapnia [42]. These values were measured relative to the daily baseline collected from the study subjects on each of the four days of the study [42].

Whereas the ventilatory rate demonstrated no significant changes across the treatment arms, the subjects receiving nalmefene exhibited both immediate and sustained recovery from morphine over the entire 6-h observation window [42]. This result for nalmefene therapy is in stark contrast to the naloxone group, which charted an initial improvement in ventilation and end-tidal $\mathrm{CO}_{2}$ before gradually returning to respiratory depression starting at approximately $2.5 \mathrm{~h}$ post-administration [42]. These results suggest that respiratory rate alone is an insufficient measure of the extent of respiratory depression while supporting the advantages to nalmefene for safe treatment of opioid toxicity over a prolonged period without the risk of the degree of short interval repeat drug administration required with naloxone [42]. This is consistent with similar research conducted by Gal et al., which is described more below.

\subsection{Gal and DiFazio Study}

A study conducted by researchers at the University of Virginia sought to quantify both the opioid antagonist activity and duration of nalmefene by pretreating subjects with varying doses of the study drug before submitting each to a 2 microgram/kilogram fentanyl challenge [55]. Values measured included quantifiable signs of respiratory depression and the patients' subjective responses to pain via a modified submaximal tourniquet ischemia test [55]. The study subjects were randomized in a double-blind fashion into one of four treatment sequences with the following: saline placebo, 0.5 milligram nalmefene, 1 milligram nalmefene, and 2 milligram nalmefene [55]. The 2-microgram fentanyl challenges were administered at 1,2, 4, 6, and $8 \mathrm{~h}$ post-administration, with the respiratory data gathered in a nearly continuous manner throughout each trial [55].

Nalmefene pretreatment resulted in consistently blunted fentanyl-induced respiratory depression, with the high-dose nalmefene arm demonstrating no change in minute ventilation concerning baseline [55]. Additionally, the analgesic effects of the varying nalmefene doses were directly parallel to the duration of resolution of the respiratory symptoms: the 2 milligram nalmefene dose resolved respiratory depression and blocked the analgesic effects of the fentanyl challenges for the duration of the 8-h experiment; the 1 milligram nalmefene dose resolved and blocked through the 6-h mark; and the $0.5 \mathrm{mg}$ nalmefene dose resolved and blocked through $4 \mathrm{~h}$ [55]. In terms of safety, no serious adverse events were reported, though one subject in the high-dose nalmefene group complained of a temporary $(10 \mathrm{~h})$ "gagging sensation" [55]. Table 2 outlines the studies discussed in this section. 
Table 2. Clinical safety and efficacy.

\begin{tabular}{|c|c|c|c|}
\hline Study Name & Groups Studied and Intervention & Results and Findings & Conclusions \\
\hline Kaplan et al. & $\begin{array}{l}171 \text { unique adult patients with } \\
\text { signs of opioid overdose who } \\
\text { presented to the emergency } \\
\text { departments of multiple urban } \\
\text { teaching hospitals were studied to } \\
\text { determine the differences between } \\
\text { nalmefene and naloxone as acute } \\
\text { pharmacotherapies for opioid } \\
\text { overdose reversal. Subjects were } \\
\text { randomized into } 1 \mathrm{mg} \text { nalmefene, } \\
2 \text { mg nalmefene, or } 2 \text { mg naloxone } \\
\text { treatment arms. }\end{array}$ & $\begin{array}{l}\text { No clinically or statistically } \\
\text { significant differences in outcome } \\
\text { were appreciated between the } \\
\text { low-dose nalmefene and naloxone } \\
\text { groups. However, while the } \\
\text { high-dose nalmefene group } \\
\text { recorded similar symptomatic } \\
\text { improvement, over } 30 \% \text { of } \\
\text { patients in that group experienced } \\
\text { adverse side effects. }\end{array}$ & $\begin{array}{l}\text { While there was no significant } \\
\text { difference in terms of } \\
\text { symptom resolution noted, } \\
\text { the generalizability of these } \\
\text { results is limited, and multiple } \\
\text { sources of statistical bias exist. }\end{array}$ \\
\hline
\end{tabular}

10 adult subjects completed the entire course of this double-blind experiment which sought to compare outcomes between intranasal (IN) and intramuscular (IM) nalmefene for treatment of

Krieter et al. acute opioid toxicity. Subjects were divided into groups and treated with varying sequences of $3 \mathrm{mg}$ IN nalmefene, $3 \mathrm{mg} 0.25 \%$ IN nalmefene-dodecyl maltoside (DDM), $1.5 \mathrm{mg}$ IN nalmefene, and $1.5 \mathrm{mg}$ IM nalmefene.
In terms of absorption, the $3 \mathrm{mg}$ $0.25 \%$ IN nalmefene-DDM demonstrated the quickest time both to maximum plasma concentration and to point of detectability in the plasma. The addition of DDM also did not appear to alter the rate of elimination of nalmefene.
However impressive the pharmacodynamic improvements, there is no evidence to support that these changes actually resulted in improved patient outcomes.
80 female patients scheduled to undergo elective caesarean deliveries were examined to determine the effects of nalmefene versus naloxone for the prophylactic treatment of opioid-induced adverse effects

Connelly et al. secondary to intrathecal spinal blocks (lidocaine w/ epinephrine, fentanyl, and morphine). Treatment regimens consisted of either saline, $0.25 \mathrm{mcg} / \mathrm{kg}$ IV nalmefene $\mathrm{q} 12 \mathrm{~h}$ for 2 doses, $0.50 \mathrm{mcg} / \mathrm{kg}$ IV nalmefene q12 h for 2 doses, or $48 \mathrm{mcg} / \mathrm{h}$ naloxone infusion.

6 male subjects were studied to analyze the nalmefene's degree of opioid antagonism and its half-life. Treatment regimens included

Konieczko et al. universal treatment with $10 \mathrm{mg} / 70 \mathrm{~kg}$ IV morphine followed by either IV saline, $0.4 \mathrm{mg} / 70 \mathrm{~kg}$ IV nalmefene, $1.6 \mathrm{mg} / 70 \mathrm{~kg}$ IV nalmefene, or $0.4 \mathrm{mg} / 70 \mathrm{~kg}$ IV naloxone.
No statistical or clinical differences were noted among the treatment arms either in reported pain levels, patient satisfaction, or the adverse effects of pruritis and nausea. However, both nalmefene groups experienced a statistically significant increase in episodes of vomiting relative to other treatment arms.
Related to the lack of evidence that prophylactic intervention changes patient outcomes and due to the increased risks of vomiting, the authors recommend that physicians treat side effects of intrathecal spinal blocks as they arise.
While the ventilatory rates showed no significant differences among treatment groups, those receiving nalmefene showed both immediate and sustained recovery over the entire $6 \mathrm{~h}$ observation period. The naloxone group showed a similar initial resolution of respiratory depression, but that resolution began to wane by approximately $2.5 \mathrm{~h}$ post-administration.
This study supports the advantages of nalmefene relative to naloxone for the safe treatment of opioid-induced respiratory depression over a prolonged period. Additionally, it suggests that respiratory rate alone is not an appropriate measure for the degree of respiratory depression. 
Table 2. Cont.

\begin{tabular}{|c|c|c|c|}
\hline Study Name & Groups Studied and Intervention & Results and Findings & Conclusions \\
\hline Gal and DiFazio & $\begin{array}{l}6 \text { male subjects were analyzed to } \\
\text { determine opioid antagonist } \\
\text { activity and duration of action of } \\
\text { nalmefene. Subjects were } \\
\text { randomized into one of } \\
\text { four sequences consisting of } \\
\text { pretreatments with either IV saline, } \\
0.5 \text { mg IV nalmefene, } 1 \mathrm{mg} \text { IV } \\
\text { nalmefene, or } 2 \text { mg IV nalmefene. } \\
\text { They were then subjected to } 2 \text { mcg } \\
\text { fentanyl challenges at } \\
\text { regular intervals. }\end{array}$ & $\begin{array}{l}\text { High-dose nalmefene resulted in } \\
\text { no changes from baseline minute } \\
\text { ventilation and completely } \\
\text { blocked fentanyl's analgesic } \\
\text { effects for the entire } 8 \mathrm{~h} \\
\text { observational period. Mid-dose } \\
\text { nalmefene prevented respiratory } \\
\text { depression and analgesia for } 6 \mathrm{~h} \text {, } \\
\text { while low-dose nalmefene } \\
\text { achieved the same for } 4 \mathrm{~h} \text {. No } \\
\text { serious adverse effects } \\
\text { were reported. }\end{array}$ & $\begin{array}{l}\text { IV nalmefene's duration of } \\
\text { action in blocking both the } \\
\text { respiratory and the analgesic } \\
\text { effects of fentanyl was directly } \\
\text { dose dependent. No } \\
\text { indication of agonist activity } \\
\text { was suggested by the } \\
\text { study outcomes. }\end{array}$ \\
\hline
\end{tabular}

\section{Conclusions}

The research nalmefene suggests that it can be a promising alternative for both acute opioid overdose and continued treatment of OUD. Its main features of interest are its prolonged DOA that surpasses that of most opioids and its ability to serve as an antidote for acute opioid overdose. It is a versatile drug in the sense that it has various routes of administration for different purposes. IV, IM, and SC can be used for respiratory depression reversal and recovery from opioid-induced sedation. Nalmefene has a greater oral bioavailability than naloxone.

However, research is limited in terms of positive research and more research should be carried out to prove the superiority over the standard of care for opioid overdose, which is naloxone.

The evolving literature is the reason why this review was created. If one was to conduct a PubMed search for "nalmefene" and "opioid overdose", there are only 11 articles to be found. These articles include reviews and only a few studies that look at different routes of nalmefene administration in the setting of opioid overdose. The difference between naloxone and nalmefene with opioids with different durations of action has not been performed, so a direct comment on which is different in clinical practice cannot be made. However, naloxone can be limited by its duration of action since many opioids may have a longer duration of action than naloxone itself. Since this could be the case, there is a potential for opioid-mediated respiratory/central nervous system depression beyond the duration of action of naloxone. This could render the potential reversal agent ineffective or inviable. This is where nalmefene could potentially come into play; however, more research should be carried out. Overdose antidotes may be pointless or viable depending on the specific opioid agent and the best practice guidelines need to be developed to help guide clinicians in managing these patients. It is important as well to consider different doses of the opioid make it challenging to define best practice guidelines. To date, there are limited data in the literature examining specific drugs and doses.

The foundational studies of nalmefene had small sample sizes in cohorts of men; however, there is growing research regarding its implications with women and others in the general population. When current study results are considered all together, they show similar trends. For example, evidence from multiple studies displayed nalmefene's prolonged dose-dependent DOA, minimal effect on vital signs, and ability to reverse respiratory depression in cases of suspected opioid overdose. The methodology for determining nalmefene's effects on a cellular level, such as with direct positron emissions and analysis of opioid receptors, was essential in piecing together its mechanism of action and pharmacokinetics. Current evidence has proved to be sufficient in most human subjects as the U.S. The FDA approved its use, and future research will allow for even better generalization of the data. 
Ensuring the safety of patients and reliable drug efficacy in urgent situations, such as opioid overdose, are priorities in drug development. The repeated studies with nalmefene have provided evidence that it is well-tolerated in humans even at 12-24 times its therapeutic doses. Its parenteral routes have been shown to provide consistent reversal of opioid-induced respiratory depression in various clinical settings and in cases of opioid overdose.

Additionally, its desired characteristic of having a DOA longer than most opioids has proven to be consistent for a variety of opioid substances, such as fentanyl, morphine, and meperidine. This can be pivotal in reducing healthcare costs, increasing patient satisfaction, and redistributing the time that healthcare staff spend monitoring opioid overdose patients given naloxone. For these vast and unwavering reasons, nalmefene could be a key factor for saving many lives in the current national opioid epidemic.

Author Contributions: Conceptualization, A.N.E., A.D.K.; writing-original draft preparation, A.N.E., T.D.R., E.M.B., M.R.A., M.C.F.; writing-review and editing, F.A., E.M.C., C.A.N., A.D.K.; supervision, A.D.K., A.M.K. All authors have read and agreed to the published version of the manuscript.

Funding: This research received no external funding.

Institutional Review Board Statement: Not applicable.

Informed Consent Statement: Not applicable.

Data Availability Statement: Data reported in this manuscript can be found on PubMed and is publically available.

Conflicts of Interest: The authors have no conflict of interest to disclose.

\section{References}

1. Latina, R.; De Marinis, M.G.; Giordano, F.; Osborn, J.F.; Giannarelli, D.; Di Biagio, E.; Varrassi, G.; Sansoni, J.; Bertini, L.; Baglio, G.; et al. Epidemiology of Chronic Pain in the Latium Region, Italy: A Cross-Sectional Study on the Clinical Characteristics of Patients Attending Pain Clinics. Pain Manag. Nurs. Off. J. Am. Soc. Pain Manag. Nurses 2019, 20, 373-381. [CrossRef]

2. Brady, K.T.; McCauley, J.L.; Back, S.E. Prescription Opioid Misuse, Abuse, and Treatment in the United States: An Update. Am. J. Psychiatry 2016, 173, 18-26. [CrossRef] [PubMed]

3. Prescription Opioid Trends in the United States-IQVIA. Available online: https://www.iqvia.com/insights/the-iqvia-institute/ reports / prescription-opioid-trends-in-the-united-states (accessed on 21 August 2021).

4. Drug Overdose Deaths I Drug Overdose ICDC Injury Center. Available online: https://www.cdc.gov / drugoverdose/deaths / index.html (accessed on 21 August 2021).

5. Trends and Geographic Patterns in Drug and Synthetic Opioid Overdose Deaths-United States, 2013-2019| MMWR. Available online: https: / / www.cdc.gov/mmwr/volumes /70/wr/mm7006a4.htm (accessed on 21 August 2021).

6. Understanding the Epidemic / CDC's Response to the Opioid Overdose Epidemic / CDC. Available online: https: / /www.cdc.gov / opioids/basics/epidemic.html (accessed on 21 August 2021).

7. Fairbairn, N.; Coffin, P.O.; Walley, A.Y. Naloxone for heroin, prescription opioid, and illicitly made fentanyl overdoses: Challenges and innovations responding to a dynamic epidemic. Int. J. Drug Policy 2017, 46, 172-179. [CrossRef] [PubMed]

8. Products-Vital Statistics Rapid Release-Provisional Drug Overdose Data. Available online: https://www.cdc.gov/nchs/nvss/ vsrr/drug-overdose-data.htm (accessed on 21 August 2021).

9. Barsan, W.G.; Seger, D.; Danzl, D.F.; Ling, L.J.; Bartlett, R.; Buncher, R.; Bryan, C. Duration of antagonistic effects of nalmefene and naloxone in opiate-induced sedation for emergency department procedures. Am. J. Emerg. Med. 1989, 7, 155-161. [CrossRef]

10. Adams, A.P.; Pybus, D.A. Delayed respiratory depression after use of fentanyl during anaesthesia. Br. Med. J. 1978, 1, 278-279. [CrossRef] [PubMed]

11. Kaplan, J.L.; Marx, J.A.; Calabro, J.J.; Gin-Shaw, S.L.; Spiller, J.D.; Spivey, W.L.; Gaddis, G.M.; Zhao, N.; Harchelroad, J. Doubleblind, randomized study of nalmefene and naloxone in emergency department patients with suspected narcotic overdose. Ann. Emerg. Med. 1999, 34, 42-50. [CrossRef]

12. Macmillan. Goodman and Gilman's The Pharmacological Basis of Therapeutics, 6th ed.; Gilman, A.G., Goodman, L.S., Gilman, A., Eds.; Macmillan: New York, NY, USA, 1980; 1843p. Available online: https://onlinelibrary.wiley.com/doi/abs/10.1002/jps.2600700533 (accessed on 21 August 2021).

13. Evans, J.M.; Hogg, M.I.J.; Lunn, J.N.; Rosen, M. Degree and Duration of Reversal by Naloxone of Effects of Morphine in Conscious Subjects. Br. Med. J. 1974, 2, 589-591. [CrossRef] 
14. FDA Grants Purdue Pharma's Nalmefene HCl Injection Fast Track Designation for the Emergency Treatment of Known or Suspected Opioid Overdose. Available online: https://www.businesswire.com/news/home/20190313005232/en/FDA-GrantsPurdue-Pharma\%E2\%80\%99s-Nalmefene-HCl-Injection-Fast-Track-Designation-for-the-Emergency-Treatment-of-Known-orSuspected-Opioid-Overdose (accessed on 21 August 2021).

15. Drobes, D.J.; Anton, R.F.; Thomas, S.E.; Voronin, K. Effects of naltrexone and nalmefene on subjective response to alcohol among non-treatment-seeking alcoholics and social drinkers. Alcohol. Clin. Exp. Res. 2004, 28, 1362-1370. [CrossRef]

16. Webster, L.R. Risk Factors for Opioid-Use Disorder and Overdose. Anesth. Analg. 2017, 125, 1741-1748. [CrossRef] [PubMed]

17. Scholl, L.; Seth, P.; Kariisa, M.; Wilson, N.; Baldwin, G. Drug and Opioid-Involved Overdose Deaths-United States, $2013-2017$. MMWR Morb. Mortal. Wkly. Rep. 2018, 67, 1419. [CrossRef]

18. Gomes, T.; Tadrous, M.; Mamdani, M.M.; Paterson, J.M.; Juurlink, D.N. The Burden of Opioid-Related Mortality in the United States. JAMA Netw. Open 2018, 1, e180217. [CrossRef]

19. Lyden, J.; Binswanger, I.A. The United States opioid epidemic. Semin. Perinatol. 2019, 43, 123-131. [CrossRef]

20. Terry, C.E. The Harrison Anti-Narcotic Act. Available online: https://ajph.aphapublications.org/doi/pdf/10.2105/AJPH.5.6.518 (accessed on 9 February 2021).

21. Morgan, J.P. American opiophobia. Adv. Alcohol Subst. Abuse 1985, 5, 163-172. [CrossRef]

22. Guy, G.P.; Zhang, K.; Bohm, M.K.; Losby, J.; Lewis, B.; Young, R.; Murphy, L.B.; Dowell, D. Vital Signs: Changes in Opioid Prescribing in the United States, 2006-2015. MMWR Morb. Mortal. Wkly. Rep. 2017, 66, 697-704. [CrossRef]

23. Donroe, J.H.; Socias, M.E.; Marshall, B.D.L. The Deepening Opioid Crisis in North America: Historical Context and Current Solutions. Curr. Addict. Rep. 2018, 5, 454-463. [CrossRef]

24. Coffa, D.; Snyder, H. Opioid use disorder: Medical treatment options. Am. Fam. Physician 2019, 100, 416-425. [PubMed]

25. Boyer, E.W. Management of Opioid Analgesic Overdose. N. Engl. J. Med. 2012, 367, 146-155. [CrossRef] [PubMed]

26. Lloyd, J. The Clinical Use of Naloxone. Available online: https://www.fda.gov/files/drugs/published/Presentation--TheClinical-Use-of-Naloxone.pdf (accessed on 20 March 2021).

27. Dunne, R.B. Prescribing naloxone for opioid overdose intervention. Pain Manag. 2018, 8, 197-208. [CrossRef]

28. Mitchell, K.D.; Higgins, L.J. Combating Opioid Overdose With Public Access to Naloxone. J. Addict. Nurs. 2016, $27,160-179$. [CrossRef]

29. Peprah, K.; Severn, M. Intranasal and Intramuscular Naloxone for Opioid Overdose in the Pre-Hospital Setting: A Review of Comparative Clinical and Cost-Effectiveness, and Guidelines [Internet]; Canadian Agency for Drugs and Technologies in Health: Ottawa, ON, Canada, 2019. Available online: https:/ / www.ncbi.nlm.nih.gov/books/NBK554777/ (accessed on 26 November 2019).

30. Substance Abuse and Mental Health Services Administration. Naltrexone. Updated 15 September 2020. Available online: https:/ / www.samhsa.gov/medication-assisted-treatment/medications-counseling-related-conditions/naltrexone (accessed on 20 September 2021).

31. Federal Drug Administration. Nalmefene. Available online: https://www.accessdata.fda.gov/drugsatfda_docs/label/2006/020 459s006lbl.pdf (accessed on 21 August 2021).

32. Tadori, Y. Pharmacological profile and clinical findings of nalmefene (Selincro ${ }^{\circledR}$ ) for reducing alcohol consumption in patients with alcohol dependence. Nihon Yakurigaku Zasshi Folia Pharmacol. Jpn. 2020, 155, 113-119. [CrossRef] [PubMed]

33. NALMEFENE (REVEX): A Longer-Lasting Opioid Antagonist. AJN Am. J. Nurs. 1996, 96, 54-55. [CrossRef]

34. Dixon, R.; Gentile, J.; Hsu, H.B.; Hsiao, J.; Howes, J.; Garg, D.; Weidler, D. Nalmefene: Safety and kinetics after single and multiple oral doses of a new opioid antagonist. J. Clin. Pharmacol. 1987, 27, 233-239. [CrossRef] [PubMed]

35. Graves, G.R.; Kennedy, T.G.; Weick, R.F.; Casper, R.F. Endocrinology: The effect of nalmefene on pulsatile secretion of luteinizing hormone and prolactin in men. Hum. Reprod. 1993, 8, 1598-1603. [CrossRef]

36. Bart, G.; Schluger, J.H.; Borg, L.; Ho, A.; Bidlack, J.M.; Kreek, M.J. Nalmefene induced elevation in serum prolactin in normal human volunteers: Partial kappa opioid agonist activity? Neuropsychopharmacol. Off. Publ. Am. Coll. Neuropsychopharmacol. 2005, 30, 2254-2262. [CrossRef] [PubMed]

37. Rose, J.H.; Karkhanis, A.N.; Steiniger-Brach, B.; Jones, S.R. Distinct Effects of Nalmefene on Dopamine Uptake Rates and Kappa Opioid Receptor Activity in the Nucleus Accumbens Following Chronic Intermittent Ethanol Exposure. Int. J. Mol. Sci. 2016, 17, 1216. [CrossRef] [PubMed]

38. Thompson, M.D.; Siminovitch, K.A.; Cole, D.E.C. G protein-coupled receptor pharmacogenetics. Methods Mol. Biol. Clifton NJ 2008, 448, 139-185. [CrossRef]

39. Dixon, R.; Howes, J.; Gentile, J.; Hsu, H.-B.; Hsiao, J.; Garg, D.; Weidler, D.; Meyer, M.; Tuttle, R. Nalmefene: Intravenous safety and kinetics of a new opioid antagonist. Clin. Pharmacol. Ther. 1986, 39, 49-53. [CrossRef] [PubMed]

40. Ingman, K.; Hagelberg, N.; Aalto, S.; Någren, K.; Juhakoski, A.; Karhuvaara, S.; Kallio, A.; Oikonen, V.; Hietala, J.; Scheinin, H. Prolonged central mu-opioid receptor occupancy after single and repeated nalmefene dosing. Neuropsychopharmacol. Off. Publ. Am. Coll. Neuropsychopharmacol. 2005, 30, 2245-2253. [CrossRef]

41. GluN2A-Selective Positive Allosteric Modulator-Nalmefene-Flumazenil Reverses Ketamine-Fentanyl-Dexmedetomidine-Induced Anesthesia and Analgesia in Rats I Scientific Reports. Available online: https:/ /www.nature.com/articles/s41598-020-62192-8 (accessed on 21 August 2021).

42. Konieczko, K.M.; Jones, J.G.; Barrowcliffe, M.P.; Jordan, C.; Altman, D.G. Antagonism of morphine-induced respiratory depression with nalmefene. Br. J. Anaesth. 1988, 61, 318-323. [CrossRef] 
43. Valentino, R.J.; Volkow, N.D. Untangling the complexity of opioid receptor function. Neuropsychopharmacol. Off. Publ. Am. Coll. Neuropsychopharmacol. 2018, 43, 2514-2520. [CrossRef]

44. Soyka, M. Nalmefene for the treatment of alcohol dependence: A current update. Int. J. Neuropsychopharmacol. 2014, 17, 675-684. [CrossRef]

45. Pattinson, K.T.S. Opioids and the control of respiration. Br. J. Anaesth. 2008, 100, 747-758. [CrossRef]

46. Wong, J. Chapter 208. Naloxone and Nalmefene. In Poisoning \& Drug Overdose; Olson, K.R., Ed.; The McGraw-Hill Companies: New York, NY, USA, 2012.

47. Frye, R.F.; Matzke, G.R.; Jallad, N.S.; Wilhelm, J.A.; Bikhazi, G.B. The effect of age on the pharmacokinetics of the opioid antagonist nalmefene. Br. J. Clin. Pharmacol. 1996, 42, 301-306. [CrossRef] [PubMed]

48. Nalmefene IC21H25NO3-PubChem. Available online: https://pubchem.ncbi.nlm.nih.gov/compound/Nalmefene (accessed on 22 August 2021).

49. Population Pharmacokinetics of Nalmefene in Healthy Subjects and Its Relation to $\mu$-Opioid Receptor Occupancy. Available online: https: / www.ncbi.nlm.nih.gov/pmc/articles/PMC4833148/ (accessed on 22 August 2021).

50. Chapter 208. Naloxone and Nalmefene I Poisoning \& Drug Overdose, 6e I AccessMedicine I McGraw Hill Medical. Available online: https: / / accessmedicine.mhmedical.com/ content.aspx?bookid=391\&sectionid=42070023 (accessed on 22 August 2021).

51. Colquhoun, R.; Tan, D.Y.K.; Hull, S. A comparison of oral and implant naltrexone outcomes at 12 months. J. Opioid Manag. 2005, 1, 249-256. [CrossRef] [PubMed]

52. Prevention of Opioid Overdose I NEJM. Available online: https:/ / www.nejm.org/doi/full/10.1056/NEJMra1807054 (accessed on 22 August 2021).

53. Krieter, P.; Gyaw, S.; Crystal, R.; Skolnick, P. Fighting fire with fire: Development of intranasal nalmefene to treat synthetic opioid overdose. J. Pharmacol. Exp. Ther. 2019, 371, 409-415. [CrossRef]

54. Connelly, N.R.; Rahimi, A.; Parker, R.K. Nalmefene or naloxone for preventing intrathecal opioid mediated side effects in cesarean delivery patients. Int. J. Obstet. Anesth. 1997, 6, 231-234. [CrossRef]

55. Gal, T.J.; DiFazio, C.A. Prolonged Antagonism of Opioid Action with Intravenous Nalmefene in Man. Anesthesiology 1986, 64, 175-180. [CrossRef] [PubMed] 